\title{
Rushton: The great theoretician and his contribution to personality
}

\author{
Donald I. Templer $*, 1$ \\ Alliant International University, Fresno, CA 93727, USA
}

\section{A R T I C L E I N F O}

\section{Article history:}

Available online $\mathrm{xxxx}$

\section{Keywords:}

Rushton

Theory

Evolution

Personality

Intelligence

\begin{abstract}
A B S T R A C T
J. Philippe Rushton has been described as one of the greatest theorists in the field of personality and individual differences and social psychology. His life history theory (Differential $K$ Theory) was said to bring unification to the scientific study of racial differences as Einstein's theory of relativity unified the field of physics. It was maintained that Rushton's General Factor of Personality (GFP) meshes with both general intelligence and his Differential $K$ Theory. The present author presented a two-pillar theory of adaptive functioning that has a heavy concentration on Rushton conceptualization.
\end{abstract}

(C) 2012 Published by Elsevier Ltd.

\section{Introduction}

There have been two books that were most influential in my career. When I was a clinical psychology graduate student in my twenties, I was unable to believe what American graduate students were supposed to believe. I could not believe that psychotherapy works very much. I could not believe that projective techniques had much validity. I could not feel a religious type fervor that people are capable of great change. Instead, I believed that our lives are very much determined by our biology. Psychology suddenly made sense to me when I read Hans Eysenck's (1957) - The Dynamics of Anxiety and Hysteria. I did not realize at the time that my theoretical orientation was essentially that of the "London School" with roots in Darwin, Galton, Spearman, Pearson, Burt, Eysenck, and Jensen. The second influential book was Rushton's, (1995) Race, Evolution and Behavior: A Life History Perspective read when I was in my sixties and a professor of psychology. I corresponded with him and met him at a conference of the International Society for Intelligence Research. He became my mentor in racial realism research.

I regard Rushton as one of the greatest theoreticians in the field of psychology. He is the great unifier. (1) He integrates psychology with the other social sciences, especially anthropology, history, and sociology. (2) He integrates psychology with the biological sciences, especially genetics, anatomy, and endocrinology. (3) He integrates psychology with animal behavior (and evolutionary theory). (4) His life history theory (Differential $K$ Theory) incorporates a vast array of behavioral, personality, biological, and social/ethnic differences. (5) His genetic similarity theory extends kin selection to the human case, integrates assortative mating and behavioral

\footnotetext{
* Tel./fax: +1559431 1886 .

E-mail address: donaldtempler@sbcglobal.net

1 Retired.
}

genetics, and explains ethnic nepotism. It has been said that "the unifying theory regarding racial differences of Rushton is the equivalent of Einstein's unification of physics by the theory of relativity" (Templer, 2004, p. 11).

Rushton, like the classical personality theorists of a century ago such as Freud and Jung and Rank is a very creative and prolific writer. Rushton's concepts, however, are more comprehensible, definable, and quantifiable. They are much more empirically verifiable and have been empirically verified. (Incidentally, I have never heard Rushton say that he is a personality theorist. Perhaps he does not want to be grouped with imprecise thinkers). His classical article in Psychological Bulletin (Rushton, Brainerd, \& Pressley, 1983) on aggregated data will endure independently of his work on intelligence and personality. In the Psych Lit system alone that article has well over 300 citations.

\section{Rushton's Differential K Theory}

The $r$ vs. $K$ differentiation of reproductive strategies and life histories of animals was introduced by MacArthur and Wilson (1967). The $r$ strategists, in contrast to $K$ strategists, have large litter size, shorter birth spacing, more offspring, less parental care, higher infant mortality, more rapid maturation, shorter life, higher reproductive effort, higher energy utilization, lower social organization, and lower altruism.

Rushton described how Blacks and East Asians (Chinese, Japanese, and Koreans) throughout the world are at opposite ends of the $r-K$ continuum with Blacks having more $r$ characteristics and East Asians having more $K$ characteristics. East Asians have larger brain size, higher intelligence based on different types of measurements, greater cultural achievements, slower motor development, slower skeletal development, slower dental development, older age of first intercourse, older age of first pregnancy, longer life 
span, lower aggressiveness, greater conscientiousness, lower dominance, less impulsivity, lower self-concept, lower sociability, higher marital stability, higher law abidingness, higher social organization, lower two-egg twinning, lower hormonal levels, smaller genitals, smaller secondary sexual characteristics, less frequent intercourse, less permissive attitude toward sex, and lower rate of sexually transmitted diseases.

The racial differences are recognized by observant and openminded people of average intelligence and education. They cannot help but notice that Blacks are greatly overrepresented in violent crime. They can't help but notice that Blacks talk louder and can be heard at a greater distance. They sing louder and play music more loudly. They are more muscular and have more of an athletic walk, are more athletically oriented and are athletically superior (Entine, 2000). Blacks talk more about sex and have more sexual awareness. On college campuses, East Asians are overrepresented in the library and underrepresented on the athletic fields.

East Asians are overrepresented in the more demanding disciplines-the physical sciences, mathematics, engineering, and pharmacy. The stereotype of difficulty of discipline is borne out in the research of Templer, Tomeo, Arikawa, and Williams (2003), who found a correlation of .76 between Verbal + Quantitative + Analytic Graduate Record Exam (GRE) and the ratio of Asians to Blacks in the discipline. The ratio was 18.16 in material engineering, 14.01 in physics, .45 in social work, and .11 in educational administration. California has three levels of state-supported educational institutions. The University of California schools are at the highest level, followed by the California State University campuses, followed by the community colleges. One almost feels like one is in an East Asian country at the University of California, Berkeley, with comparatively few Black students. This situation definitely does not prevail at the community colleges.

The race aspect of Rushton's life history theory may be the most controversial and most important with respect to social implications. It is, however, only one aspect of a very encompassing perspective. Life history theory involves sexual behavior, number of offspring, parenting, health, life expectancy, impulse control, aggression, cooperation, and altruism. Intelligence and brain size are probably the most important determinants of this cluster of variables. In Rushton's theory, greater intelligence develops in colder climates because of the greater difficulty in obtaining and preserving food, making warm clothing, constructing shelters, and raising children to maturity.

Rushton's life history theory (Differential $K$ Theory) is internally consistent. It makes sense. More importantly, there is good empirical support for Rushton's contention that greater intelligence develops in cold climates. There is also good empirical support for Rushton's contention that his important variables interrelated, as he said they should.

The research of Templer and Arikawa (2006) supports Rushton's contention that higher intelligence develops in colder climates. They used 129 countries with primarily indigenous populations (Asia, Africa, and Europe) and correlated culture fair IQ (Lynn \& Vanhanen, 2002) with temperature. In addition to temperature, Templer and Arikawa used skin color provided by an anthropology book (Biasutti, 1967). IQ correlated .92 with darker skin color, -.76 with winter highs, -.66 with winter lows, and .63 with per capita income. Previous research by Meisenberg (2004) reported a correlation of .89 between skin reflectance and IQ in a similar study. Templer (2010b) found a correlation of .96 between skin color measure used by the Templer and Arikawa and the one by Meisenberg's skin reflectance. Because both measures were independently determined using different methodology, they both can be regarded as highly valid measures of skin color.

The research of Templer (2008) attempted to determine whether Rushton's $r-K$ variables intercorrelate in the expected direction. Templer intercorrelated IQ, birth rate, infant mortality, HIV/AIDS, and life expectancy across 129 countries. All of the correlations were in the direction predicted on the basis of Differential $K$ Theory. A $K$ super factor accounted for $75 \%$ of the variance. The correlations were significantly higher with skin color, a biological variable, than with gross domestic product, a culturally influenced variable. The median of the 21 intercorrelations among the seven variables was 68 .

Rushton's broadly encompassing theory provides a structure into which other theories and explanations could be blended with rather than necessarily pitted against. Science itself is a consilient process in which additions and adjustments and corrections must be made. Rushton and associates seem to view evolution as a more overriding concept than climate. Templer (2010a) said, "Neither Rushton nor Lynn has ever claimed that climate is the only variable in the evolution of intelligence. Both acknowledge that the high intelligence in Ashkenazi Jews could be a function of selection for those surviving maltreatment over the centuries. If I had to use one word to describe the impetus for evolutionary change in intelligence, it would be "challenge" because that word implies both adversity and opportunity (p. 103). Hawks, Wang, Cochran, Harpending, and Moyzis (2007) maintained that evolution speeded up around 10,000 years ago and that this was based less on physical environment than on cultural environments with new types of technology, social structure, and codified behavior. Lynn (2011) attributed the high intelligence of Ashkenazi Jews not only to adversity but to the more intelligent, such as rabbis having more children and the heavy involvement in money-related occupations. Cochran, Hardy, and Harpending (2006) attributed the evolving high intelligence primarily to their occupations which fostered verbal and mathematical (but not spatial) superiority. Cochran et al. doubt the contribution of persecution because gypsies have also been persecuted but do not have a high IQ. Cochran et al. attributed the unpretentious intelligence of Jews living in Islamic lands as a function of their not having commerce-related occupations and being sometimes relegated to "dirty jobs." Tropical birds have more reproductive and parenting $K$ characteristics (Pianka, 1970). This appears to be a function of the unpredictability of colder climates making survival more difficult. The brains of birds are simply too small for the evolution of greater cognitive development that happens with humans in cold climates.

According to Rushton, the more intelligent produce fewer children. This is unquestionably true when one looks at the current situation within countries and across countries of the world. This generalization does not hold up with all place and time considerations. Both Clark (2007) and Lynn (2011) maintained that prior to the industrial revolution the English upper classes outbred the poor whose children had a higher mortality rate. Improved nutrition and sanitation for the poor and the use of the condom by the wealthy reversed the situation.

\section{Rushton's General Factor of Personality (GFP)}

The GFP, like all of Rushton's ideas, is very much consistent with common sense. It is to personality as little $g$ of Spearman and Jensen. The roots of the GFP are in his statement that "one basic dimension-K-underlies much of the field of personality" (Rushton, 1985, p. 445). Rushton and Irwing (2009c, p. 356) succinctly described the person high in GFP as "altruistic, emotionally stable, agreeable, conscientious, extraverted, intellectually open, and mentally tough with high level of well-being, satisfaction with life, self-esteem, and emotionally intelligent," and they state that the person low in GFP is generally maladjusted and likely to have a personality disorder. This includes research using the Millon Clinical Multiaxial Inventory, an instrument that assesses personality 
disorders and character defects (Rushton \& Irwing, 2009a) and research using a variety of general personality inventories (Erdle, Irwing, Rushton, \& Park, 2010; Rushton \& Irwing, 2009b). Rushton and Irwing (2011) described the historical roots of the GFP and they pointed out that Darwin and Galton before them also viewed favorable personality characteristics as having evolved because they contributed to the success of the individual and society. The GFP correlations for identical twins are higher than for fraternal twins (Rushton \& Irwing, 2008, 2009c). Other research provides strong support for genetic influence (Figueredo \& Rushton, 2009; Figueredo, Vasquez, Brumbach, \& Schneider, 2004). Van der Linden, te Nijenhuis, and Bakker (2010) reported a massive meta-analysis of Big Five interrelations that included 212 studies and 144,117 participants. GFP accounted for $45 \%$ of the variance. Van der Linden, te Nijenhuis, Cremers, and van de Ven (2011), using six large data sets and six personality questionnaires with 21,754 members of the Netherlands armed forces. For each of the six data sets, a meaningful GFP was found.

The GFP appears to be related to important real-life situations. In the research of van der Linden et al. (2011), GFP was related to drop-out from military training. Van der Linden, Scholte, Cillesen, te Nijenhuis, and Segers (2010) found the GFP was related to likeability and popularity in junior high school students. Van der Linden et al. (2010) reported GFP to be related to supervisor-rated job performance.

\section{Two Pillars of General Adaptive Functioning}

The following biological theoretical formulation is my own but is heavily influenced by the work of Rushton and associates. It is here maintained that there are two biological pillars of general adaptive function. One is $g$ of Spearman (1927) and Jensen (1998). The other is Rushton's GFP. If one assumes as suggested above that $r-K$ is to group and races as GFP is to individuals, Rushton's Differential $K$ Theory fits into my two-pillar theory.

Axis V of the Diagnostic and Statistical Manual-IV (DSM-IV) of the American Psychiatric Association is a 1-to-100 rating scale. "Superior functioning in a wide range of activities, life's problems never seem to get out of hand, is sought out by others because of his or her many positive qualities" (p. 34) merits a score from 91-to-100. "Persistent danger of severely hurting self or others (e.g., recurrent violence) or persistent inability to maintain minimum personal hygiene or serious suicidal act with clear expectation of death" (p. 34) merits a score of $0-10$. The present author's formulation was intended to apply more to the big domain of adaptive function than to Axis $\mathrm{V}$ per se.

The two pillars are only slightly correlational with each other in high-functioning people. In fact, the California Psychological Inventory (CPI) Manual (Gough, 1987), presents 334 correlations between the CPI scales and cognitive/intellectual measures. Only 22 of these correlations are over .30. With below-average intelligence people, however, the two pillars are more highly correlated. Herrnstein and Murray (1994) presented a plethora of evidence that people who are less bright function less well. Below-average IQ people do less well in school, are more likely to be unemployed, are more accident prone, are more likely to be physically disabled, commit more crime, and are more likely to be on welfare. In mental retardation, the inadequacy and dysfunction in behavior are even more prominent. One study found that only $13 \%$ of retarded children were free of psychiatric disorder and that $26 \%$ were psychotic (Gath \& Gumley, 1986). Placement in institutions is often precipitated by maladaptive behavior such as hitting, kicking, biting, fecal and urinary incontinence, and public masturbation. Failure at job placement was often associated with aggressive or irritating or annoying behavior (Foss \& Peterson, 1981). It should be noted that borderline and mild mental retardation are more likely to be of genetic etiology in contrast to moderate, severe, and profound retardation that are more likely to be caused by a medical condition or trauma early in life.

In most people and throughout their life history, the two pillars are determined primarily by genetics. Assault to the brain, however, can lower cognitive and personality functioning. These assaults to the brain could be short term, such as alcohol or drug intoxication. Brain disorders, however, are often permanent. Brain tumors can cause general intellectual decline, memory difficulty, personality deterioration, and psychosis. The early symptoms of Huntington's chorea are slovenly habits, irresponsibility, lower moral standards, and emotional lability. Next come choreic movements and general intellectual decline. In Alzheimer's disease, one progresses from forgetfulness to poor judgment, and then to dementia and incontinence and death. Both depression and psychoses are common (Wragg \& Jeste, 1989). The symptoms of Pick's disease and Alzheimer's disease are similar, with the former having more personality deterioration and the latter more cognitive deterioration. Epileptics have a high suicide rate (Mathews \& Barabas, 1981). A disproportionate number of persons in prisons are epileptic (Hermann \& Whiteman, 1984). A quarter of epileptics with normal IQ have at least one psychiatric hospitalization (Stevens, Milstein, \& Goldstein, 1972).

The structure under two pillars is supported by the combined strength of the two pillars. In psychology, as in civil engineering, weaknesses in one pillar can be compensated for by the other. Examples of higher intelligence predicting more favorable prognosis are seen in conduct disorder (Bassarath (2001), alcoholism (Gibbs \& Flanagan, 1977), legal difficulty in drug abuse (Knapp, Templer, Cannon, \& Dobson, 1991), mentally retarded sex offenders (Rice, Harris, Lang, \& Chaplin, 2008), child molestation (Willis \& Grace, 2008), and delinquent girls 10-14 years (Maskin, 1974).

How do life events fit into the two-pillar biological theory. Not even the most radical biological determinist can deny that such events as loss of a loved one, loss of a job, divorce, or disabling injury can have an effect on one's functioning. I view biology as determining one's life course and life events as producing deviations from the trajectory.

\section{Conclusion}

Previous psychologists obtained eminence by writing that early life events have a strong bearing on behavior and functioning of the individual. Rushton, although not disparaging such positions, went further by contending that evolution of thousands of years influences present behavior and personality of individuals and of groups/races. Previous psychologists have obtained eminence by their work on intelligence and others by their work on personality. Rushton maintained that the same evolutionary process that determines intelligence determines personality and behavior. Lower GFP, more $r$ life history characteristics, lower $g$, and lower two-pillar adaptive functioning tend to be associated with antisocial behavior, aggression, and crime.

\section{References}

Bassarath, L. (2001). Conduct disorder: A biopsychosocial review. Canadian Journal of Psychiatry, 46(7), 609-616.

Biasutti, R. (1967). Le Razze e I Popoli Della Terra. Torino, Italy: Unione TipograficoEditrice Torinese.

Clark, G. (2007). A farewell to alms. A brief economic history of the world. Princeton and Oxford: Princeton University Press.

Cochran, G. M., Hardy, J., \& Harpending, H. (2006). The natural history of Ashkenazi intelligence. Journal of Biosocial Science, 38, 659-693.

Entine, J. (2000). TABOO: Why Black athletes dominate sports and why we are afraid to talk about it. New York: Public Affairs. 
Erdle, S., Irwing, P., Rushton, J. P., \& Park, J. (2010). The General Factor of Personality and its relation to self-esteem in 628,640 Internet respondents. Personality and Individual Differences, 48, 343-346.

Eysenck, H. J. (1957). The dynamics of anxiety and hysteria: An experimental application of modern learning theory to psychiatry. London: Routledge \& Kegan Paul.

Figueredo, A. J., \& Rushton, J. P. (2009). Evidence for shared genetic dominance between the General Factor of Personality, mental and physical health, and life history traits. Twin Research and Human Genetics, 12(6), 555-563.

Figueredo, A. J., Vasquez, G., Brumbach, B. H., \& Schneider, S. M. R. (2004). The inheritability of life history strategy: The $K$-factor, covitality, and personality. Social Biology, 51, 121-143.

Foss, G., \& Peterson, S. L. (1981). Social-interpersonal skills relevant to job tenure for mentally retarded adults. Mental Retardation, 19(3), 103-106.

Gath, A., \& Gumley, D. (1986). Behaviour problems in retarded children with special reference to Down's syndrome. British Journal of Psychiatry, 149, 156-161.

Gibbs, L., \& Flanagan, J. (1977). Prognostic indicators of alcoholism treatment outcome. International Journal of the Addictions, 12, 1097-1141.

Gough, H. G. (1987). California psychological inventory administrator's guide. Palo Alto, CA: Consulting Psychologists Press, Inc.

Hawks, J., Wang, E. T., Cochran, G. M., Harpending, H., \& Moyzis, R. K. (2007). Recent acceleration of human adaptive evolution. Proceedings of the National Academy of Sciences (USA), 104, 20753-20758.

Hermann, B. P., \& Whiteman, S. (1984). Behavioral and personality correlates of epilepsy: A review, methodological critique, and conceptual model. Psychological Bulletin, 95(3), 451-497.

Herrnstein, R. J., \& Murray, C. (1994). The Bell Curve: Intelligence and class structure in American life. New York: Free Press.

Jensen, A. R. (1998). The $g$ factor. Westport, CT: Praeger.

Knapp, J. E., Templer, D. I., Cannon, W. G., \& Dobson, S. (1991). Variables associated with success in an adolescent drug treatment program. Adolescence, 26(102), 305-307.

Lynn, R. (2011). The chosen people: A study of Jewish intelligence and achievement. Washington Summit Publishers.

Lynn, R., \& Vanhanen, T. (2002). IQ and the wealth of nations. Westport, CT: Praeger.

MacArthur, R. H., \& Wilson, E. O. (1967). The theory of island biogeography. Princeton, NJ: Princeton University Press.

Maskin, M. B. (1974). A comparison of graduate and recidivist WISC IQ scores in a delinquency treatment program for girls. Journal of Clinical Psychology, 30(3), 210-319.

Mathews, M. S., \& Barabas, G. (1981). Suicide in epilepsy: A review of the literature. Psychosomatics, 22, 515-524.

Meisenberg, G. (2004). Talent, character and the dimensions of national culture. Mankind Quarterly, 45, 123-168.

Pianka, E. R. (1970). On r- and K-selection. The American Naturalist, 104, 592597.

Rice, M. E., Harris, G. T., Lang, C., \& Chaplin, T. C. (2008). The sexual preferences and recidivism of sex offenders with mental retardation. Sexual Abuse, 20(4), 409-425.

Rushton, J. P. (1985). Differential $K$ theory: The sociobiology of individual and group differences. Personality and Individual Differences, 6, 441-452.

Rushton, J. P. (1995). Race, evolution, and behavior: A life history perspective. Transaction; New York: Brunswick, NJ.
Rushton, J. P., Brainerd, C. J., \& Pressley, M. (1983). Behavioral development and construct validity. The principle of aggregation. Psychological Bulletin, 94(1), $18-38$.

Rushton, J. P., \& Irwing, P. (2008). A General Factor of Personality (GFP) from two meta-analyses of the Big Five: Digman (1997) and Mount, Barrick, Scullen, and Rounds (2005). Personality and Individual Differences, 45, 679-683.

Rushton, J. P., \& Irwing, P. (2009a). A General Factor of Personality in the Millon Clinical Multiaxial Inventory-III, the Dimensional Assessment of Personality Pathology, and the Personality Assessment Inventory. Journal of Research in Personality, 43, 1091-1095.

Rushton, J. P., \& Irwing, P. (2009b). A General Factor of Personality in 16 sets of the Big Five, the Guilford-Zimmerman Temperament Survey, the California Psychological Inventory, and the Temperament and Character Inventory. Personality and Individual Differences, 47, 558-564.

Rushton, J. P., \& Irwing, P. (2009c). A General Factor of Personality (GFP) from the Multidimensional Personality Questionnaire. Personality and Individual Differences, 47, 571-576.

Rushton, J. P., \& Irwing, P. (2011). The General Factor of Personality: Normal and abnormal. In T. Chamorro-Premuzic, S. von Stumm, \& A. Furnham (Eds.), The Wiley-Blackwell handbook of individual differences. Hoboken, NJ: WileyBlackwell.

Spearman, C. (1927). The Abilities of Man. New York: Macmillan.

Stevens, J. R., Milstein, V., \& Goldstein, S. (1972). Psychometric test performance in relation to the psychopathology of epilepsy. Archives of General Psychiatry, 26, $532-538$.

Templer, D. I. (2004). The Bell Curve: An assessment after ten years. The Occidental Quarterly, 4(3), 7-20.

Templer, D. I. (2008). Correlational and factor analytic support for Rushton's differential $K$ life history theory. Personality and Individual Differences, 45, 440-444.

Templer, D. I. (2010a). Can't see the forest because of the trees. Personality and Individual Differences, 48, 102-103.

Templer, D. I. (2010b). IQ and skin color: The old world reexamined and the new world. Mankind Quarterly, 51, 3-25.

Templer, D. I., \& Arikawa, H. (2006). Temperature, skin color, per capita income, and IQ: An international perspective. Intelligence, 34, 121-139.

Templer, D. I., Tomeo, M. E., Arikawa, H., \& Williams, R. (2003). Asian-Black differences in aptitude and difficulty of chosen academic discipline. Personality and Individual Differences, 35, 237-241.

Van der Linden, D. Scholte, R. J. H., Cillesen, A. H. N., te Nijenhuis, J. \& Segers, E. (2010). The General Factor of Personality and classroom ratings of likeability and popularity. Journal of Research in Personality, 44, 669-672.

Van der Linden, D., te Nijenhuis, J., \& Bakker, A. (2010). Searching for a General Factor of Personality: A meta-analysis of Big Five correlations and two criterion validity studies. Journal of Research in Personality, 44, 315-327.

Van der Linden, D., te Nijenhuis, J., Cremers, M., \& van de Ven, D. (2011). General factors of personality in six datasets and a criterion-related validity study in the Royal Netherlands' Armed Forces. International Journal of Selection and Assessment, 19, 157-169.

Willis, G. M., \& Grace, R. C. (2008). The quality of community reintegration planning for child molesters: Effects on sexual recidivism. Sexual Abuse, 20(2), 218-240.

Wragg, R. E., \& Jeste, D. V. (1989). Overview of depression and psychosis in Alzheimer's disease. American Journal of Psychiatry, 146(5), 577-587. 